\title{
SACRO-COCCYGEAL TERATOMA
}

\author{
BY \\ JAMES LISTER \\ From the Royal Edinburgh Hospital for Sick Children
}

(RECEIVED FOR PUBLICATION AUGUST 13, 1954)

Teratomata, by reason of their bizarre nature and relatively rare occurrence, have aroused interest for many centuries. The main sites of occurrence in order of frequency are the gonads, the retroperitoneal region, the anterior mediastinum, presacral and coccygeal regions and the base of the skull (Willis, 1953). Calbet (cited by Riker and Potts, 1948) calculated that a sacro-coccygeal tumour occurred in every 34,582 births; of these a relatively small proportion were teratomata.

The first known record of a sacro-coccygeal teratoma was made on a cuneiform tablet in about 2000 B.C. and was stored in the Royal Library of Nineveh (Ballantyne, 1894). Amongst thousands of tablets found there, one dealt with the portents of monstrous births and various deformities found in newly born infants. On this tablet it was stated that 'when a woman gives birth to an infant that has three feet, two in their normal position (attached to the body) and the third between them, there will be great prosperity in the land'. There the Chaldeans left it; perhaps it was not in the national interest to interfere with such a favourable omen.

During the past century numerous cases have been reported and the first successful excision of such a tumour was reported by Stanley in 1841.

\section{Pathology}

The tumours are situated in the pre-sacral or pre-coccygeal region and may either be quite small and pedunculated, or very large and extending in all directions, both upwards into the pelvis and downwards to form a visible tumour. They contain numerous cysts, set in solid material, and sometimes well organized tissues, such as a loop of bowel or even a digit. The tumours are quite well encapsulated, but the larger ones are adherent to the anterior surface of the coccyx and sacrum and sometimes to the pubis; they usually encircle the rectum and are adherent to it (Fig. 1).

Microscopically, like any other teratoma, the tumours contain derivatives of all three germ layers. The benign tumours contain adult tissues, but the malignant tumours often contain embryonic tissues. Nervous tissue is a very common component in the solid parts and the cysts may be lined with ependyma and have fringes of choroid plexuses. Other cysts are lined with bronchial or alimentary mucosa and

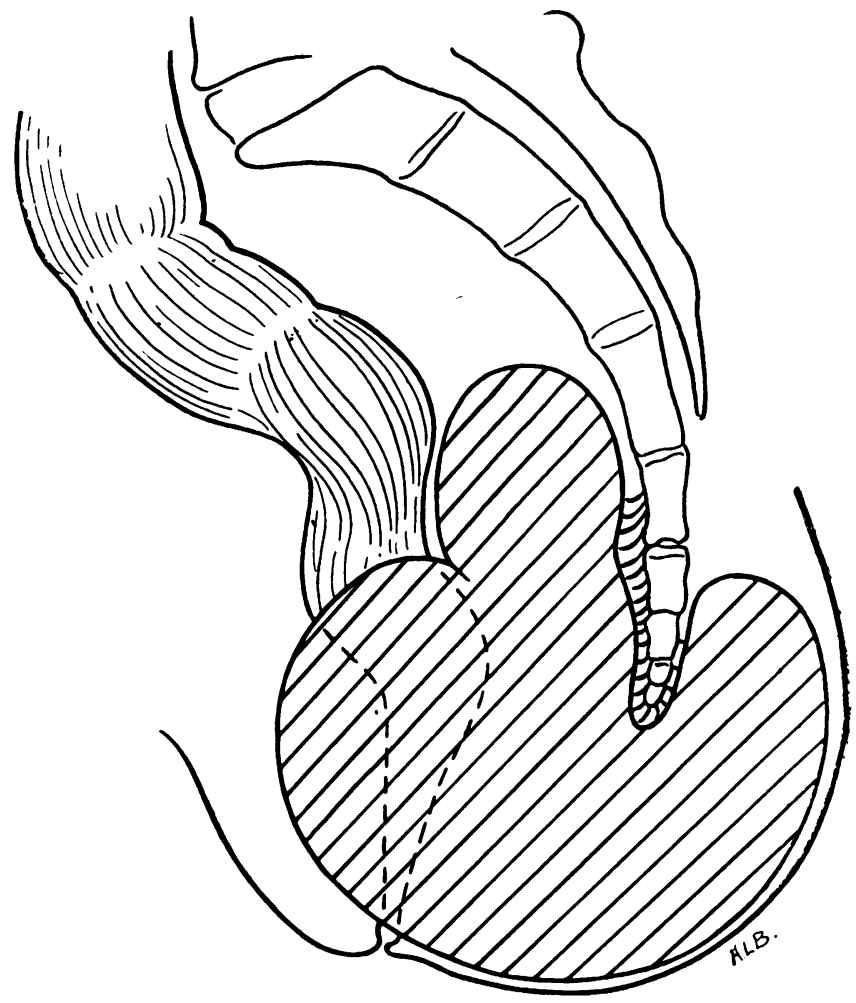

Fig. 1.-Diagram to demonstrate the extent of the large sacro-coccygeal teratoma. The tumour is encircling the rectum and is adherent to the lower part of the sacrum and to the coccyx. 
there may be adjoining solid parts containing associated tissues, such as pancreas. Connective tissue, cartilage and bone are common constituents.

It appears that sacro-coccygeal teratomata are more common in females than in males (Chaffin, 1939; Gross, Clatworthy and Meeker, 1951). This is not borne out by the relatively small number recorded in the Royal Edinburgh Hospital for Sick Children during the past 30 years (four male and five female).

The tumours are usually apparent at birth and most are benign cystic growths in the first place. A proportion, however, possibly as many as $20 \%$, become malignant and usually this malignancy is confined to one element. The most common malignant development is that of a papillary adenocarcinoma (Lisco, 1942).

\section{Histiogenesis}

A popular belief has been that there is a relationship between twins and teratomata; this conception includes both inclusion twins and parthenogenesis. Willis (1953) emphatically denies such a relationship. He states that a teratoma is a true tumour which cannot live apart from its host and yet contains tissues foreign to the situation in which it lies and has the property of uncoordinated growth apart from the growth of its host. It would appear, therefore, that teratomata arise from primordial cells which have escaped the influence of the primary organizers.

The sacro-coccygeal teratomata develop in a region where, during development, there is a great concentration of primordial cells at the primitive knot. Cells escaping the influence of the primary organizers could come direct from the primitive knot or, at a later stage, from the urogenital ridge. These cells could then develop into a teratoma. It is of interest that two cases of sacro-coccygeal teratoma treated in the Royal Edinburgh Hospital for Sick Children had also gross anomalies of the genitalia.

\section{Diagnosis}

The large majority of the tumours are noted at birth in the form of a swelling in the area between the coccyx and the anus. The swelling may be small and situated to one side of the mid-line, or it may be very large - as large as the baby's head-and displace the coccyx backwards, and the anus forwards. The most important differential diagnosis is spina bifida in its varying grades and locations. Anterior or lateral meningocoeles are excessively rare and unlikely to cause confusion. A small multilocular meningocoele with fibro-fatty angio- matous tissue around it is directed backwards, and not forwards as is the teratoma. The teratoma is covered with true skin, whereas the larger myelomeningocoele has a thin transparent membrane covering it. Many swellings associated with spina bifida demonstrate their connexion with the subarachnoid space by having a crying impulse and causing bulging of the fontanelle on compression. Of course, the more severe myelomeningocoele will have associated paralysis and hydrocephalus. Chordoma may occur in the sacro-coccygeal region, but is very rare in infants. Ependymoma, hernia and duplication of the rectum are other remote possibilities.

Rectal examination will reveal the extent of the tumour upwards into the pelvis and occasionally the tumour may be so large that it can be felt on examination of the abdomen.

Radiographs may show bone or calcification in the tumour; they will also help to exclude meningocoele or chordoma by excluding spina bifida and bone destruction.

\section{Complications}

Obstruction of the rectum or urethra may be produced by a large pelvic extension of the tumour. The overlying skin may ulcerate with possible fistulous formation from a cyst. This complication may be produced by aspiration of the cysts. The size of the tumour may be so great that it interferes with normal life, occasionally preventing walking or even sitting. The possibility of malignant change is quite a serious one as has been mentioned previously. Hypersecretion of endocrine glandular elements may occur (Rhoden, 1944).

\section{Treatment}

From a consideration of the potential complications it is evident that excision of the tumour is the only possible line of treatment. In view of the possibility of malignant change it seems that excision should be carried out at an early stage. Those tumours which appear large enough to cause obstructive symptoms should be removed as soon after birth as possible, while others should be removed as soon as the child has reached a reasonable size, i.e., at the age of 3 months.

The excision of the small pedunculated tumours presents no great problem. The large tumours, however, follow such a definite pattern in their direction of growth that a technique has been described for their removal (Gross et al., 1951). This is discussed in the case report. 


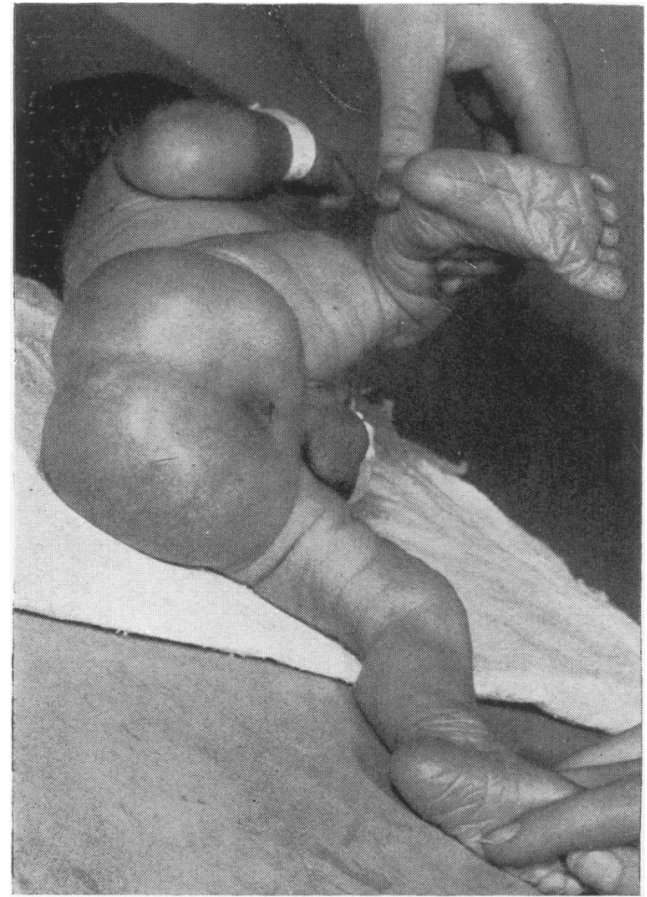

F1G. 2.-Clinical photograph showing the position and size of the tumour.

Case Report

The mother of Baby R. was admitted to a maternity unit on May 4, 1954, with mild preeclampsia. Labour was induced on May 9, 1954, and a full-time male child was delivered. It was a vertex presentation and there was a short delay in the delivery of the breech. Birth weight was $6 \mathrm{lb}$. $6 \frac{3}{4} \mathrm{oz}$.

The general condition of the baby was satisfactory at birth but he was found to have a large sacro-coccygeal tumour. The tumour was a little smaller than the baby's head and the anus appeared to lie on its anterior wall.

The baby passed urine and meconium and did not appear to have any systemic upset. He was transferred to the Royal Edinburgh Hospital for Sick Children on the day following birth (May 10).

Examination. On examination, the baby appeared quite healthy and no abnormalities were found other than the large tumour in the sacro-coccygeal region. There was a large swelling over each buttock extending forwards on either side of the anus. The anus was pushed forwards, the two projections of the tumour almost meeting anterior to the anus, just posterior to the scrotum (Fig. 2). The tumour was mainly cystic, but a few nodular areas could be palpated in it. It was covered by normal skin. Rectal examination showed that it extended upwards to the promontory of the sacrum, lying posterior to the rectum, but partly extending lateral to it on either side.

The tumour was so large that it was felt that it should be removed in order to avoid any obstructive complications.

Operation. Before operation, on May 13, two intravenous drips were set up, one into the left arm and one into the left leg. The baby was placed in the inverted ' $V$ ' position. Cyclopropane and oxygen were administered through an endotracheal tube. A gauze swab was inserted into the rectum to prevent soiling and to facilitate its identification.

A transverse elliptical incision was made across the tumour. The upper flap was mobilized until the edge of the tumour was defined and then the lateral margins were dissected free. After the lower skin flap had been dissected forwards as far as the anal sphincter, a plane of cleavage was found between the tumour and the gluteal muscles and the ischium and sacrum. The tumour was adherent to the sacro-coccygeal region and the coccyx was disarticulated. The upward prolongation of the tumour between the sacrum and rectum was then easily separated. When the rectum was defined the tumour was separated easily from it and from the levator ani and sphincter muscles. In the lower part the tumour passed on both sides of the rectum.

After removal of the tumour in this way the levator ani

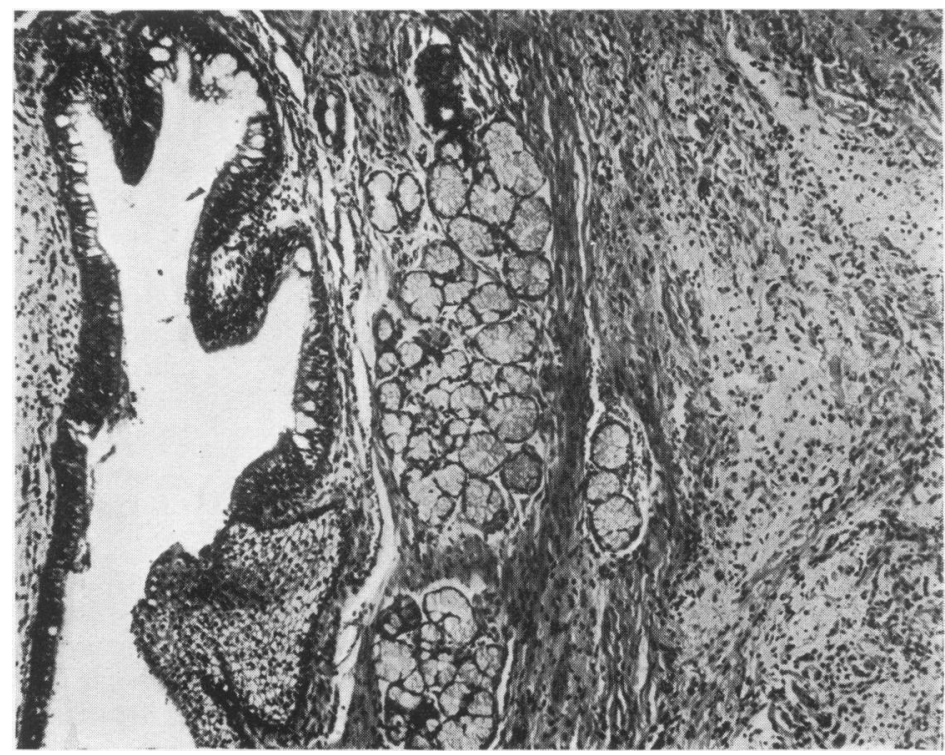

FIG. 3.-Photomicrograph showing cyst lined with columnar epithelium ciliated in parts, mucous glands, muscle and glial tissue. These are derivatives of all three germ layers. 
was reconstituted and the sphincter muscles reattached to it. The subcutaneous tissues were sutured with catgut and the skin closed with interrupted silk sutures. Two small drains were left in the resulting dead space.

Progress. During the operation $240 \mathrm{ml}$. of blood were given and the baby's condition was satisfactory after operation. He was nursed on a framebed to avoid contamination of the wound by faeces. Urine was drained by Paul's tubing attached to the penis. The bowels moved on the first post-operative day. The drains were removed on the fifth day and the sutures on the tenth day. Thereafter progress was uninterrupted.

Pathology. The pathological report described the tumour as an irregular cystic mass measuring $7.5 \mathrm{~cm}$. by $7.0 \mathrm{~cm}$. at its longest and broadest points; one of the larger cysts had ruptured during excision. A cylindrical projection in the deepest part was made up of small cysts and a crumbling tissue. The cysts contained serous fluid and had smooth walls. One of the larger cysts had an irregular, velvety lining and contained loose bodies.

Microscopical examination (Figs. 3 and 4) showed a variety of well differentiated tissues mixed in great confusion. The deep projection was glial tissue with some nerve cells and nerve trunks. Close by was a quantity of smooth muscle. The cysts here were lined with squamous or columnar epithelium. The cysts nearer the surface were lined with epithelium, which was squamous, cuboidal or columnar and sometimes ciliated, and some had ependymal lining with papillary structures resembling a choroid plexus. One cyst had an alimentary epithelial lining with duodenal (Brunner) glands and adjacent to it was a mass of pancreatic tissue containing acini, ducts and poorly differentiated islets. Sympathetic ganglia were seen and the large cyst with a velvety lining was lined by a thin layer of brain tissue covered by epithelium; the loose bodies were of brain tissue.

The solid parts showed a mixture of nervous tissue, muscle, both striped and smooth, fibrous tissue, adipose tissue and cartilage. The most abundant tissue was brain tissue.

\section{Summary}

Sacro-coccygeal teratoma is a rare congenital tumour.

Because of the risk of malignant change early removal of the tumour is indicated. Removal may

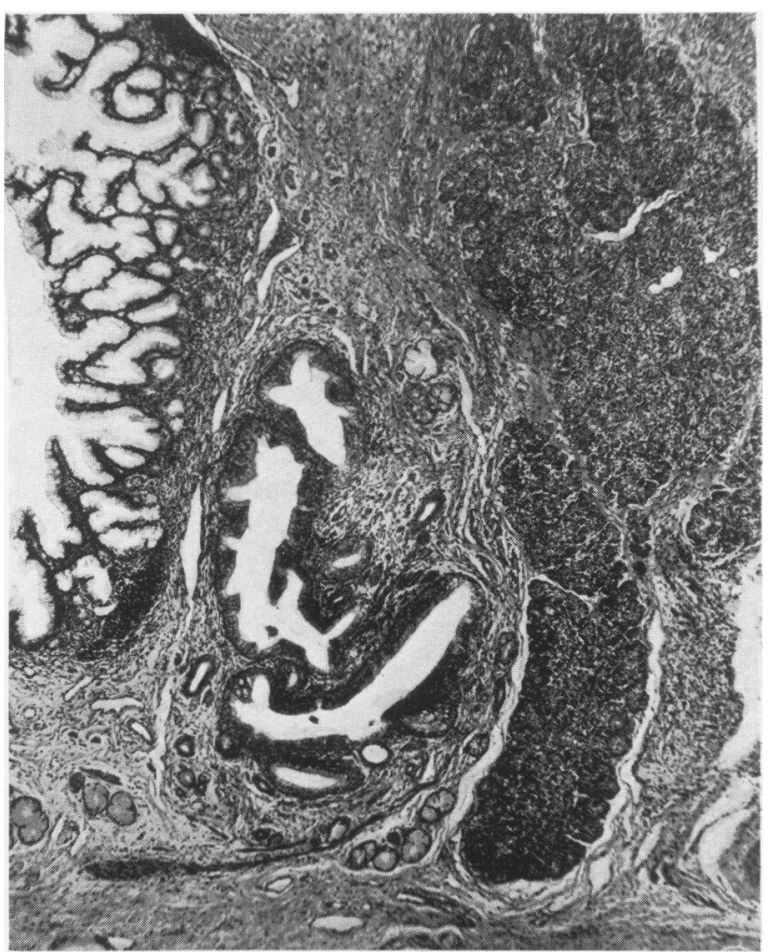

FIG. 4.-Photomicrograph showing cyst lined with alimentary mucosa, duodenal glands close by, pancreatic tissue in the lower right part of the field and, to the right of that, structure resembling a sympathetic ganglion.

be necessary in the first few days of life in order to avoid obstructive complications.

A case is described emphasizing the technique described by Gross for the removal of such tumours.

I am grateful to Mr. J. J. Mason Brown for permission to publish this case which was under his care. It is also a pleasure to express my indebtedness to Miss A. R. Macgregor for the pathological report.

\section{REFERENCES}

Ballantyne, J. W. (1894). Teratologia: A Quarterly Journal o, Antenatal Pathology, Vol. 1, p. 133. London.

Chaffin, L. (1939). Surg. Gynec. Obstet., 69, 337.

Gross, R. E., Clatworthy, H. W., Jr., and Meeker, I. A., Jr. (1951). Ibid., 92, 341 .

Lisco, H. (1942). Ann. Surg., 115, 378.

Rhoden, A. E. (1944). J. clin. Endocr., 4, 185

Riker, W. and Potts, W. J. (1948). Ann. Surg., 128, 89

Stanley, E. (1841). Med.-Chir. Trans. Lond., 24, 235.

Willis, R. A. (1953). Pathology of Tumours, 2nd ed., p. 940. London. 